\title{
Chiral separation by SMB chromatography
}

\author{
Luís S. Pais, José M. Loureiro, Alírio E. Rodrigues * \\ Laboratory of Separation and Reaction Engineering, School of Engineering, University of Porto, Rua dos Bragas, \\ 4050-123 Porto, Portugal
}

\begin{abstract}
The paper deals with chiral separation by simulated moving bed (SMB) chromatography. A model for the prediction of the cyclic steady-state performance of the SMB, based on the analogy with the true moving bed (TMB), is developed assuming multicomponent adsorption equilibria, axial dispersion flow and the linear driving force approximation to describe the intraparticle mass transfer rate. The simulation package is used to predict the effect of operating variables on the process performance and to define the regions for enantiomers separation. The influence of mass transfer resistance in the separation region is analyzed. A practical tool for choosing the better SMB operating conditions as a function of the feed flow-rate is proposed. The experimental operation of a pilot unit of SMB, Licosep 12-26 (Novasep, France), is carried out for the separation of enantiomers and illustrated with two systems: the bi-naphthol and the chiral epoxide enantiomers. Experimental results and model predictions are compared in terms of process performance and internal concentration profiles. (C) 2000 Elsevier Science B.V. All rights reserved.
\end{abstract}

Keywords: Simulated moving bed chromatography; Computer simulation and optimization; Chiral separation; Bi-naphthol enantiomers; Chiral epoxide enantiomers

\section{Nomenclature}

$\begin{array}{ll}c & \text { fluid phase concentration } \\ D_{\mathrm{L}} & \text { axial dispersion coefficient } \\ k & \text { mass transfer coefficient } \\ L_{j} & \text { length of section } j \\ \text { PR } & \text { adsorbent productivity } \\ \text { PUR } & \text { raffinate purity } \\ \text { PUX } & \text { extract purity } \\ \text { Pe } & \text { Peclet number } \\ Q & \text { volumetric liquid flow-rate }\end{array}$

\footnotetext{
* Corresponding author. Tel.: + 351-22-2041671; fax: + 351-22-2041674

E-mail address: arodrig@fe.up.pt (A.E. Rodrigues)
} 


$\begin{array}{ll}Q_{\mathrm{s}} & \text { solid flow-rate } \\ q & \text { average adsorbed phase concentration } \\ q^{*} & \text { adsorbed concentration in equilibrium with } c \\ \text { RCR } & \text { raffinate recovery } \\ \text { RCX } & \text { extract recovery } \\ \mathrm{SC} & \text { solvent consumption } \\ t^{*} & \text { switch time interval } \\ u_{\mathrm{s}} & \text { solid velocity } \\ V_{\mathrm{T}} & \text { volume of the adsorbent bed } \\ v_{j} & \text { interstitial fluid velocity } \\ z & \text { axial coordinate }\end{array}$

Greek symbols:

$\alpha_{j}$

$\varepsilon$

$\gamma_{j}$

\section{Subscripts and}

superscripts:

$\begin{array}{ll}\text { A } & \text { less retained component } \\ \text { B } & \text { more retained component } \\ \text { E } & \text { eluent } \\ \text { F } & \text { feed } \\ \text { R } & \text { raffinate } \\ \text { X } & \text { extract }\end{array}$

number of mass transfer units

bed porosity

ratio between fluid and solid velocities

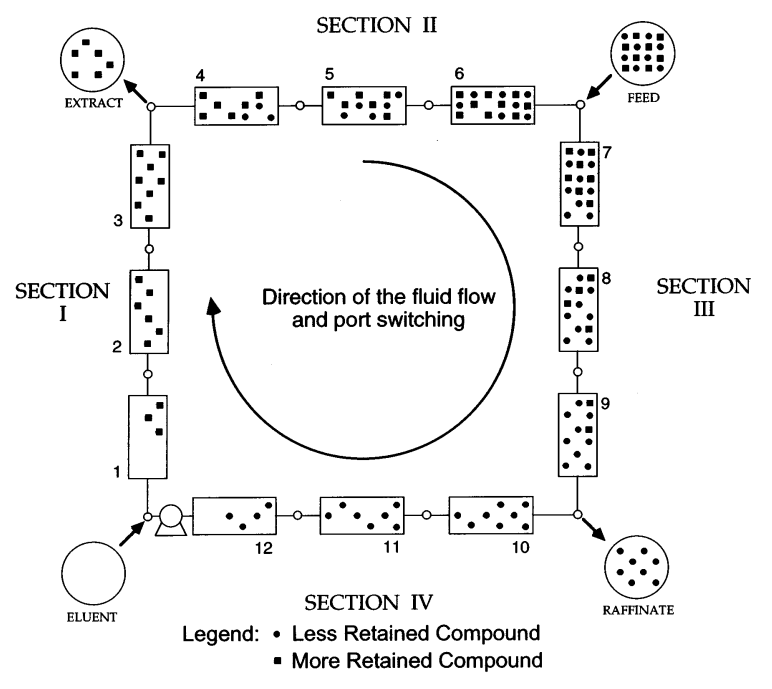

Fig. 1. Schematic diagram of a simulated moving bed (SMB).

\section{Introduction}

The simulated moving bed (SMB) technology [1-3] is receiving an increasing interest as an alternative technique for the production of fine chemicals and pharmaceuticals. Recent works proved the efficiency of this technology at lab scale, and first industrial applications have been mentioned. Following the new regulations regarding the approval of new pharmaceutical drugs, SMB chromatographic separation systems have been developed in order to obtain single enantiomer drugs.

Briefly, the SMB technology allows the continuous injection and separation of binary mixtures. The simulated countercurrent contact between the solid and liquid phases maximizes the mass-trans- 


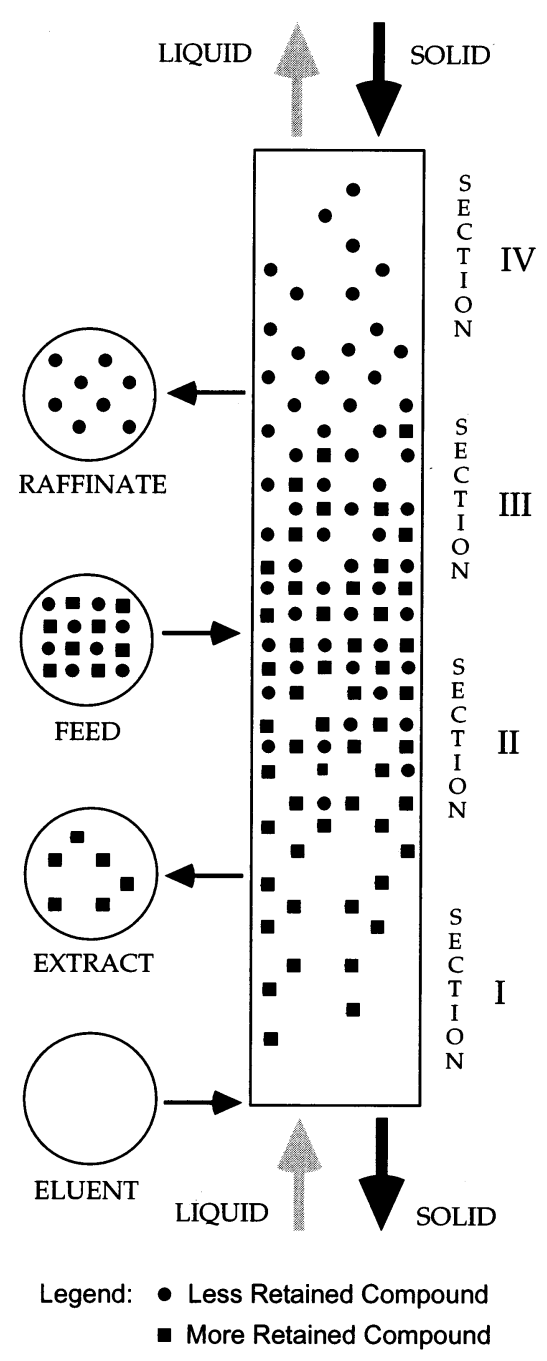

Fig. 2. Schematic diagram of a true moving bed (TMB).

fer driving force, leading to a significant reduction in mobile and stationary phases consumption when compared with elution chromatography. This countercurrent movement is simulated by an appropriated flow switching sequence: the adsorbent bed is divided into a number of fixed-bed columns, while the inlet and outlet lines move simultaneously one column at fixed time intervals in the direction of the liquid phase flow (Fig. 1).

Small scale SMB units constitute a useful tool for the pharmaceutical industry. For preliminary biological tests, only a few grams of the chiral drug are needed. Furthermore, SMB can provide the two pure enantiomers, which are required for comparative biological testing [4]. On the other hand, pharmaceutical companies work with short drug development times. SMB technology, combined with proper chromatographic chiral stationary phases now available, can be a quick system, easily to set up, enhancing at the same time a high throughput of drug material [5]. Nevertheless, the use of SMB technology in the pharmaceutical industry is not limited to laboratory tests. Its use at production scale is being considered as an alternative to up to now leading techniques such as enantioselective synthesis or diastereoisomeric crystallization. Large scale chromatographic separations were in the past limited, mainly due to the high cost of the adsorbent, the high dilution of products, and the large amounts of mobile phase needed. With the introduction of the SMB technology, large scale separations can now be carried out under cost-effective conditions [6,7]. Moreover, in large scale chiral separation processes, new trends are being developed like coupling SMB with other techniques such as racemization and enantioselective crystallization [8].

The selection of the SMB operating conditions is not straightforward. The main problem of the SMB operation consists in choosing the right solid (switch time interval) and liquid flow-rates. Designed for high productivity separations, SMB units usually operate at high feed concentrations leading to non-linear competitive adsorption behaviours. Therefore, modeling and simulation tools are of crucial importance before running the system.

\section{SMB strategies of modeling}

Different models to predict the performance of a SMB separation process have been proposed in the literature. Two main strategies can be carried out to model a SMB system: one, the SMB model (Fig. 1), that considers the real shift of the injection and collection points; the other, the true moving bed (TMB, Fig. 2) model, that considers liquid and solid flow in opposite directions.

The predictions of these two models were compared in terms of steady-state performance for the 
separation of bi-naphthol enantiomers. Also, the influence of the degree of subdivision of the bed in the SMB model predictions was analyzed and compared with the TMB performance. A complete study, with comparison between experimental and model results, can be found elsewhere [9]. The main conclusion of this study is that the deviations between TMB and SMB predictions (averaged over a switch time interval) decrease as the degree of subdivision of the bed increases. For practical purposes, optimization and choice of SMB configuration (length of each section) can be safely carried out on the basis of analogy with TMB modeling.

Although transient evolution of the SMB and TMB approaches are different, they have similar steady-state performances. Since the primary ob-

Table 1

Model equations for the steady-state true moving bed (TMB) model $^{\mathrm{a}}$

Mass balance in a volume element of the bed $j$ :

$D_{\mathrm{L}_{j}} \frac{\mathrm{d}^{2} c_{i j}}{\mathrm{~d} z^{2}}-v_{j} \frac{\mathrm{d} c_{i j}}{\mathrm{~d} z}-\frac{(1-\varepsilon)}{\varepsilon} k\left(q_{i j}^{*}-q_{i j}\right)=0$

Mass balance in the particle:

$u_{\mathrm{s}} \frac{\mathrm{d} q_{i j}}{\mathrm{~d} z}+k\left(q_{i j}^{*}-q_{i j}\right)=0$

Boundary conditions for section $j$ :

$z=0: \quad c_{i j}-\frac{D_{\mathrm{L}_{j}}}{v_{j}} \frac{\mathrm{d} c_{i j}}{\mathrm{~d} z}=c_{i j, 0}$

where $c_{i j, 0}$ is the inlet concentration of species $i$ in section $j$ :

$$
\begin{array}{rlrl}
z=L_{j}: & c_{i j}=c_{i j+1,0} & \begin{array}{l}
\text { for extract and } \\
\text { raffinate nodes }
\end{array} \\
c_{i j}=\frac{v_{\mathrm{I}}}{v_{\mathrm{IV}}} c_{i j+1,0} & \begin{array}{l}
\text { for the eluent } \\
\text { node }
\end{array} \\
c_{i j}=\frac{v_{\mathrm{III}}}{v_{\mathrm{II}}} c_{i j+1,0} & \begin{array}{l}
\text { for the feed } \\
\text { node }
\end{array} \\
& -\frac{v_{\mathrm{F}}}{v_{\mathrm{II}}} c_{i}^{\mathrm{F}} &
\end{array}
$$$$
\text { and } \quad q_{i j}=q_{i j+1,0}
$$

Global balances:

$$
\begin{array}{ll}
v_{\mathrm{I}}=v_{\mathrm{IV}}+v_{\mathrm{E}} & \text { eluent node } \\
v_{\mathrm{II}}=v_{\mathrm{I}}-v_{\mathrm{X}} & \text { extract node } \\
v_{\mathrm{III}}=v_{\mathrm{II}}+v_{\mathrm{F}} & \text { feed node } \\
v_{\mathrm{IV}}=v_{\mathrm{III}}-v_{\mathrm{R}} & \text { raffinate node }
\end{array}
$$

Multicomponent adsorption equilibrium isotherm:

$q_{\mathrm{A}_{j}}^{*}=f_{\mathrm{A}}\left(c_{\mathrm{A}_{j}}, c_{\mathrm{B}_{j}}\right)$ and $q_{\mathrm{B}_{j}}^{*}=f_{\mathrm{B}}\left(c_{\mathrm{A}_{j}}, c_{\mathrm{B}_{j}}\right)$

\footnotetext{
${ }^{\mathrm{a}}$ In the above equations, $i=\mathrm{A}$, B refers to the species in the mixture, and $j=\mathrm{I}$, II, III, IV is the section number.
}

jective is to characterize steady-state performance, one can simulate and obtain the optimum operating conditions for the SMB using the steady-state TMB model. Thereby, the problem consisting in a PDEs system can be reduced to an ODEs system, which requires lower computing times.

The package developed for the steady-state TMB model considers axial dispersion flow for the bulk fluid phase and the linear driving force (LDF) approximation is used to describe the intraparticle mass transfer rate. The model can handle any kind of adsorption isotherm. Model equations for the steady-state TMB model are summarized in Table 1 with the boundary conditions, as well as with the necessary mass balances at the nodes between each section. The resulting model parameters are:

$(1-\varepsilon) / \varepsilon$,

the ratio between solid and fluid volumes;

$\gamma_{j}=v_{j} / u_{\mathrm{s}}$,

the ratio between fluid and solid velocities;

$\mathrm{Pe}_{j}=v_{j} L_{j} / D_{\mathrm{L} j}, \quad$ Peclet number;

$\alpha_{j}=k L_{j} / u_{\mathrm{s}}$, number of mass transfer units.

The model equations were numerically solved by using the COLNEW software [10] which implements a finite-element collocation technique for mixed-order systems of linear or nonlinear boundary-value ordinary differential equations.

\section{Simulation results}

The SMB performance can be characterized by four process parameters: purity, recovery, solvent consumption and adsorbent productivity. Table 2 defines these process performance parameters for the case of a binary separation in which the less retained species $A$ is recovered in the raffinate and the more retained component $\mathrm{B}$ is recovered in the extract.

The effect of the operating and model parameters on the SMB performance and so the choice of the better SMB operating conditions can be carried out using the TMB model presented before. 
Table 2

Simulated moving bed (SMB) performance criteria

\begin{tabular}{|c|c|c|}
\hline $\begin{array}{l}\text { Performance } \\
\text { parameter }\end{array}$ & Extract & Raffinate \\
\hline Purity $(\%)$ & $\begin{array}{l}\text { PUX } \\
=100 C_{\mathrm{B}}^{\mathrm{X}} /\left(C_{\mathrm{A}}^{\mathrm{X}}+C_{\mathrm{B}}^{\mathrm{X}}\right)\end{array}$ & $\begin{array}{l}\text { PUR } \\
=100 C_{\mathrm{A}}^{\mathrm{R}} /\left(C_{\mathrm{A}}^{\mathrm{R}}+C_{\mathrm{B}}^{\mathrm{R}}\right)\end{array}$ \\
\hline Recovery $(\%)$ & $\begin{array}{l}\mathrm{RCX} \\
=100 Q_{\mathrm{X}} C_{\mathrm{B}}^{\mathrm{X}} / Q_{\mathrm{F}} C_{\mathrm{B}}^{\mathrm{F}}\end{array}$ & $\begin{array}{l}\mathrm{RCR} \\
=100 Q_{\mathrm{R}} C_{\mathrm{A}}^{\mathrm{R}} / Q_{\mathrm{F}} C_{\mathrm{A}}^{\mathrm{F}}\end{array}$ \\
\hline $\begin{array}{l}\text { Solvent } \\
\text { consumption } \\
(1 / \mathrm{g})\end{array}$ & \multicolumn{2}{|c|}{$\mathrm{SC}=\left(Q_{\mathrm{E}}+Q_{\mathrm{F}}\right) /\left[Q_{\mathrm{F}}\left(C_{\mathrm{A}}^{\mathrm{F}}+C_{\mathrm{B}}^{\mathrm{F}}\right)\right]$} \\
\hline $\begin{array}{l}\text { Productivity } \\
\text { (g/day } 1 \text { of } \\
\text { bed) }\end{array}$ & \multicolumn{2}{|l|}{$\mathrm{PR}=Q_{\mathrm{F}}\left(C_{\mathrm{A}}^{\mathrm{F}}+C_{\mathrm{B}}^{\mathrm{F}}\right) / V_{\mathrm{T}}$} \\
\hline
\end{tabular}

Table 3

True moving bed (TMB) operating conditions and model parameters used in simulations

\begin{tabular}{|c|c|}
\hline $\begin{array}{l}\text { TMB operation } \\
\text { conditions }\end{array}$ & Model parameters \\
\hline $\begin{array}{l}\text { Feed concentration: } 2.9 \\
\mathrm{~g} / 1 \text { each }\end{array}$ & $\begin{array}{l}\text { Solid/fluid volumes: } \\
(1-\varepsilon) / \varepsilon=1.5\end{array}$ \\
\hline $\begin{array}{l}\text { Solid flow-rate: } 11.15 \\
\mathrm{ml} / \mathrm{min}\end{array}$ & Peclet number: $P e=2000$ \\
\hline $\begin{array}{l}\text { Recycling flow-rate: } \\
27.95 \mathrm{ml} / \mathrm{min}\end{array}$ & $\begin{array}{l}\text { Ratio between fluid and solid } \\
\text { velocities }\end{array}$ \\
\hline $\begin{array}{l}\text { Column diameter: } 2.6 \\
\mathrm{~cm}\end{array}$ & In zone IV: $\gamma_{\mathrm{IV}}=3.76$ \\
\hline Zone length: $21.0 \mathrm{~cm}$ & \\
\hline
\end{tabular}

In this study, the separation of bi-naphthol enantiomers is used as illustrative example. The purified bi-naphthol enantiomers are used as chiral building blocks in asymmetric synthesis and as catalysts in some chemical reactions. The enantioseparation can be carried out using 3,5-dinitrobenzoyl phenylglycine bonded to silica gel as stationary phase and heptane-isopropanol (72:28) as eluent [11,12]. A bi-Langmuir model is proposed to describe the adsorption equilibrium isotherms, which were measured by the Novasep group [13]:

$$
\begin{aligned}
& q_{\mathrm{A}}^{*}=\frac{2.69 c_{\mathrm{A}}}{1+0.0336 c_{\mathrm{A}}+0.0466 c_{\mathrm{B}}}+\frac{0.10 c_{\mathrm{A}}}{1+c_{\mathrm{A}}+3 c_{\mathrm{B}}} \\
& q_{\mathrm{B}}^{*}=\frac{3.73 c_{\mathrm{B}}}{1+0.0336 c_{\mathrm{A}}+0.0466 c_{\mathrm{B}}}+\frac{0.30 c_{\mathrm{B}}}{1+c_{\mathrm{A}}+3 c_{\mathrm{B}}}
\end{aligned}
$$

The conditions for enantiomers separation can be defined in terms of the $\gamma_{j}$ model parameters, which are directly related with the TMB operating variables (fluid and solid velocities in the four sections of the TMB unit). Ruthven and Ching [14] derived the optimum TMB flow conditions for linear isotherms. However, for non-linear competitive adsorption isotherms, which is the common case in chiral separations, the selection of the SMB operating conditions is not straightforward. The conditions for complete enantiomer separation were analyzed in the frame of the equilibrium theory, where mass transfer resistances and axial dispersion are neglected $[15,16]$ Nevertheless, if mass transfer resistance is important, the region for complete separation is reduced and $100 \%$ pure enantiomers may not be obtained. In these cases, a purity criteria can be proposed and the region for separation (where both enantiomers purities are at least equal to the proposed purity criteria) can be evaluated. The region for enantiomer separation can then be numerically predicted considering the mass transfer resistance.

Simulations were carried out for the bi-naphthol system, keeping constant the recycling (flowrate in Section 4) and solid flow-rates. The TMB operating conditions and model parameters are summarized in Table 3. A recycling flow-rate of $27.95 \mathrm{ml} / \mathrm{min}$ in the TMB corresponds to a recycling flow-rate of $35.38 \mathrm{ml} / \mathrm{min}$ in the SMB; a TMB solid flow-rate of $11.15 \mathrm{ml} / \mathrm{min}$ corresponds to a switch time interval of $3 \mathrm{~min}$ in the SMB unit [9]. The total inlet or outlet flow-rates were kept constant in all simulations and equal to 25.09 $\mathrm{ml} / \mathrm{min}$.

For practical purposes, it is desirable to work with variables directly related with the SMB unit. Instead of presenting the separation region in terms of $\gamma_{j}$ values, the same information can be reported in a $Q_{\mathrm{X}}$ versus $Q_{\mathrm{F}}$ plot. Eqs. (9) and (10) present the conversion rules between the TMB 


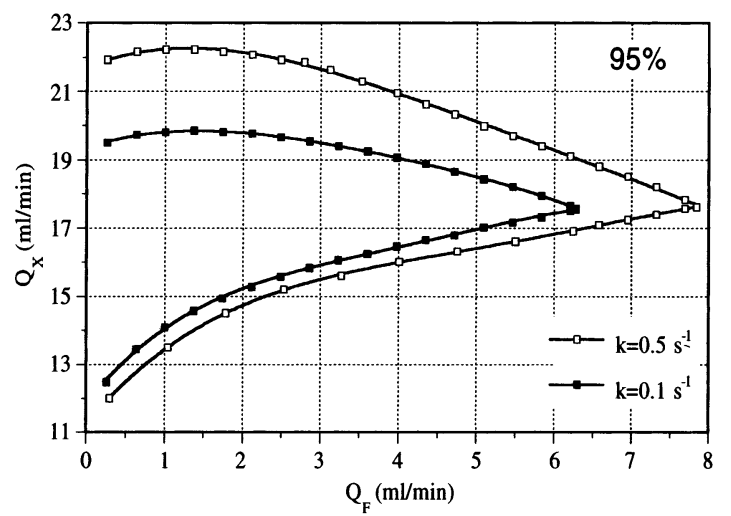

Fig. 3. Influence of the mass transfer resistance on the separation region: $Q_{\mathrm{X}}$ vs. $Q_{\mathrm{F}}$ plot for a $95 \%$ purity criteria ( $\square$ for $k=0.5 \mathrm{~s}^{-1} ; \mathbf{\square}$ for $\left.k=0.1 \mathrm{~s}^{-1}\right)$.

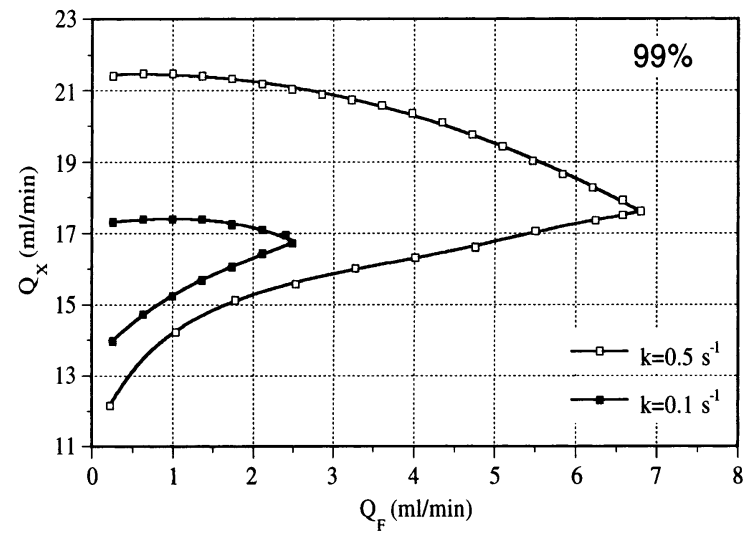

Fig. 4. Influence of the mass transfer resistance on the separation region: $Q_{\mathrm{X}}$ vs. $Q_{\mathrm{F}}$ plot for a $99 \%$ purity criteria ( $\square$ for $k=0.5 \mathrm{~s}^{-1} ; \mathbf{\square}$ for $\left.k=0.1 \mathrm{~s}^{-1}\right)$. operating conditions and feed and extract flowrates. The eluent flow-rate will be $25.09-Q_{\mathrm{F}}$ and the raffinate flow-rate $25.09-Q_{\mathrm{x}}$.

$Q_{\mathrm{F}}=\frac{\varepsilon}{1-\varepsilon}\left(\gamma_{\mathrm{III}}-\gamma_{\mathrm{II}}\right) Q_{\mathrm{s}}$

$Q_{\mathrm{X}}=\frac{\varepsilon}{1-\varepsilon}\left(\gamma_{\mathrm{I}}-\gamma_{\mathrm{II}}\right) Q_{\mathrm{s}}$

Figs. 3 and 4 show the influence of mass transfer resistance on the separation region. The $Q_{\mathrm{x}}$ versus $Q_{\mathrm{F}}$ plots were numerically obtained for a mass transfer coefficient of $k=0.5 \mathrm{~s}^{-1}(\alpha=180)$ (open squares) and $k=0.1 \mathrm{~s}^{-1}(\alpha=36)$ (closed squares) using a 95\% (Fig. 3) and 99\% (Fig. 4) purity criteria. Inside the region delimited by the square points, both the raffinate and the extract are at least $95 \%$ or $99 \%$ pure. It can be concluded that mass transfer resistance reduces the separation region of both enantiomers and that the region obtained for a lower mass transfer coefficient $\left(k=0.1 \mathrm{~s}^{-1}\right)$ lies inside the region obtained when mass transfer resistance is not so important $\left(k=0.5 \mathrm{~s}^{-1}\right)$.

In these figures, the vertex of the separation region points out the better operating conditions, since it is the point where the purity criteria is fulfilled with a higher feed flow-rate (lower eluent flow-rate). Hence, in the operating conditions specified by the vertex point, both solvent consumption and adsorbent productivity are optimized. Comparing the vertex points obtained for the two values of mass transfer coefficient, it can be concluded that the mass transfer resistance influences the better SMB operating conditions. Table 4 presents the better SMB operating conditions and stresses out the influence of the mass transfer

Table 4

Influence of the mass transfer resistance on the optimum simulated moving bed (SMB) operating conditions, and corresponding solvent consumption and productivity performances ${ }^{\mathrm{a}}$

\begin{tabular}{llllllll}
\hline $\begin{array}{l}\text { Purity } \\
\text { requirement (\%) }\end{array}$ & $k\left(\mathrm{~s}^{-1}\right)$ & $Q_{E}(\mathrm{ml} / \mathrm{min})$ & $Q_{\mathrm{X}}(\mathrm{ml} / \mathrm{min})$ & $Q_{\mathrm{F}}(\mathrm{ml} / \mathrm{min})$ & $Q_{\mathrm{R}}(\mathrm{ml} / \mathrm{min})$ & $\mathrm{SC}(\lambda / \mathrm{g})$ & $\begin{array}{l}\mathrm{PR}(\mathrm{g} / \mathrm{day} \text { per } \lambda \\
\text { of bed })\end{array}$ \\
\hline 95 & 0.5 & 17.24 & 17.62 & 7.85 & 7.47 & 0.55 & 147.0 \\
& 0.1 & 18.84 & 17.57 & 6.25 & 7.52 & 0.69 & 117.0 \\
99 & 0.5 & 18.29 & 17.62 & 6.80 & 7.47 & 0.64 & 127.3 \\
& 0.1 & 22.70 & 16.90 & 2.39 & 8.19 & 1.81 & 44.8 \\
\hline
\end{tabular}

\footnotetext{
${ }^{\text {a }}$ Comparison between 95 and $99 \%$ purity requirements.
} 


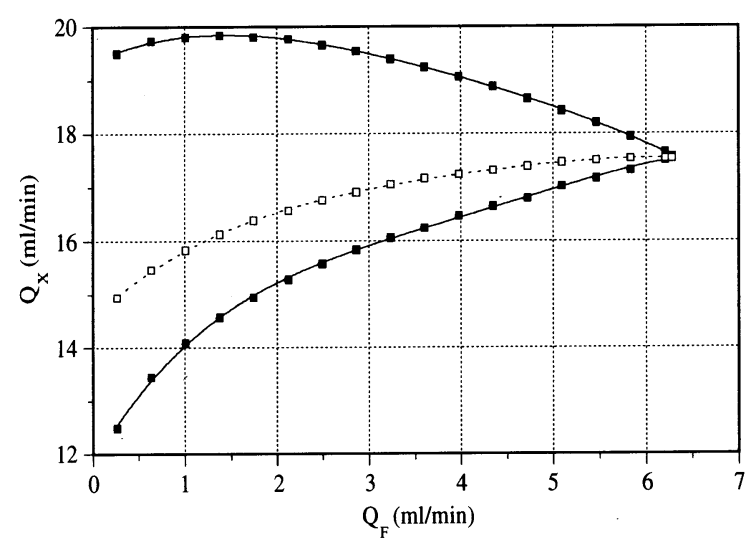

Fig. 5. Separation region in a $Q_{\mathrm{X}}$ vs. $Q_{\mathrm{F}}$ plot ( $\left.\mathbf{\square}\right)$. $\square$ present the path of equal raffinate and extract purities (mass transfer coefficient, $k=0.1 \mathrm{~s}^{-1}$; purity criteria: $95 \%$ ).

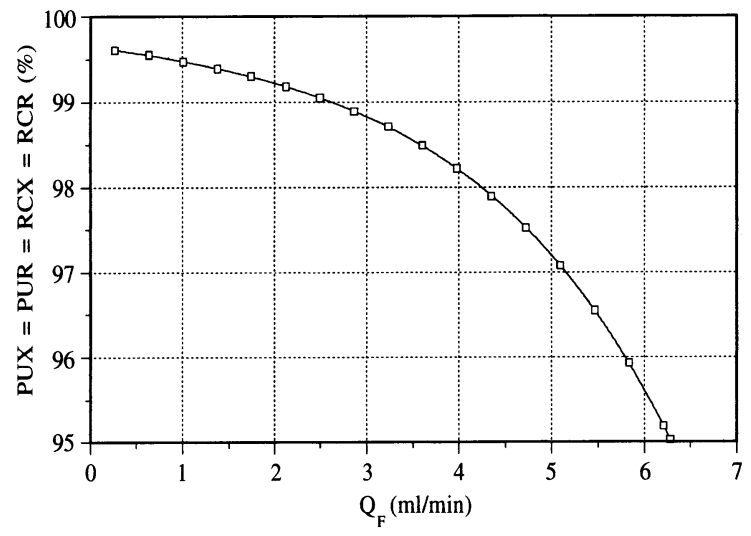

Fig. 6. Optimum purities and recoveries as a function of the feed flow-rate.

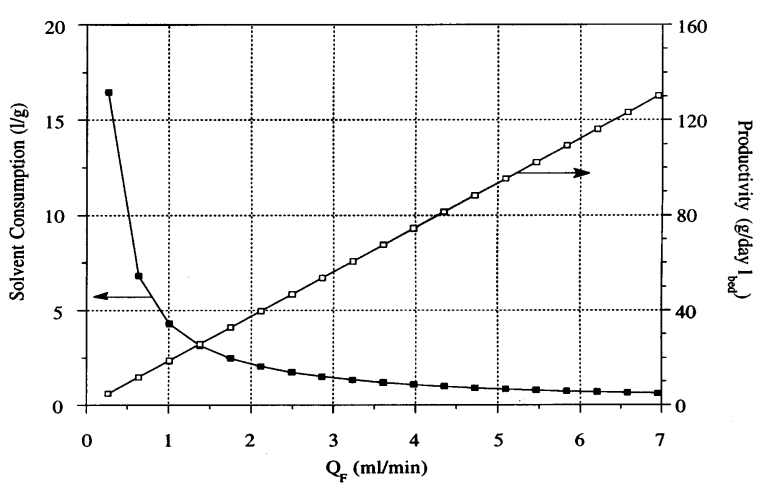

Fig. 7. Solvent consumption and adsorbent productivity as a function of the feed flow-rate. resistance. If mass transfer resistance is important $\left(k=0.1 \mathrm{~s}^{-1}\right)$, a lower feed flow-rate must be used to obtain the desired product purity. Moreover, this influence is emphasized when a higher purity requirement is desired. For example, if $99 \%$ pure extract and raffinate is needed, a feed flow-rate of $2.39 \mathrm{ml} / \mathrm{min}$ must be used, instead of $6.80 \mathrm{ml} / \mathrm{min}$ when mass transfer resistance is negligible $(k=0.5$ $\mathrm{s}^{-1}$ ). The productivity performance will be consequently diminished by a factor of 2.8 .

The separation region for $k=0.1 \mathrm{~s}^{-1}$ following a $95 \%$ purity criteria is presented in Fig. 5. In the region limited by the closed squares both raffinate and extract purities are at least 95\%. Open squares show the path of equal purities for extract and raffinate. Since the objective of the SMB operation is to obtain the two enantiomers, the path of equal purities is the optimum trajectory that must be followed [17].

Fig. 6 presents the optimum purities (and recoveries) that can be expected for a given feed flow-rate. It should be pointed out that, when racemic mixtures are fed into a SMB unit, if extract and raffinate purities are equal, recoveries of both extract and raffinate are also equal and with the same value of the purity obtained. Fig. 7 presents the solvent consumption and adsorbent productivity obtained as a function of the feed flow-rate. Of course, this figure should not be used without looking for Fig. 6: the increase of the feed flow-rate leads to better solvent consumption and productivity performances, but it is followed by a decrease in both purities and recoveries of extract and raffinate. Furthermore, the higher the feed flow-rate, the smaller the range of extract flow-rates that lead to both enantiomer separation. This means that the process robustness also decreases with the increase of the feed flow-rate.

\section{Experimental operation of a SMB pilot unit}

The SMB pilot unit used in this work is the Licosep 12-26, developed by Novasep (Vandoeuvre-lès-Nancy, France) in cooperation with the Institut Français du Pétrole (Rueil-Malmaison, France). Two systems are considered as illustra- 
Table 5

Experimental simulated moving bed (SMB) operating conditions for the bi-naphthol enantiomers

\begin{tabular}{lr}
\hline Feed concentration $(\mathrm{g} / \mathrm{l}$ each) & 2.9 \\
\hline Flow-rates $(\mathrm{ml} / \mathrm{min})$ : & \\
Recycling & 35.38 \\
Eluent & 21.45 \\
Extract & 16.00 \\
Feed & 3.64 \\
Raffinate & 9.09 \\
\hline
\end{tabular}

tive examples of SMB chiral separations: the binaphthol and the chiral epoxide enantiomers.

The operation of the SMB pilot for the binaphthol enantiomers (Aldrich, USA, Cat. No. 10,465-5) was carried out using an eight-column configuration (two per section). Columns are made of 3,5-dinitrobenzoyl phenylglycine bonded to silica gel (Merck, Darmstadt, Germany). Each column is $2.6 \mathrm{~cm}$ ID $\times 10.5 \mathrm{~cm}$ long. Silica particles have diameter in the range $25-40 \mu \mathrm{m}$. The eluent used was a $72 / 28(\mathrm{v} / \mathrm{v})$ heptane-isopropanol mixture. Operation temperature was fixed at $25^{\circ} \mathrm{C}$ $[11,12]$.

Five runs were carried out to study the effect of the switch time interval on the SMB process performance. Table 5 presents the experimental conditions for the SMB pilot. The internal profiles

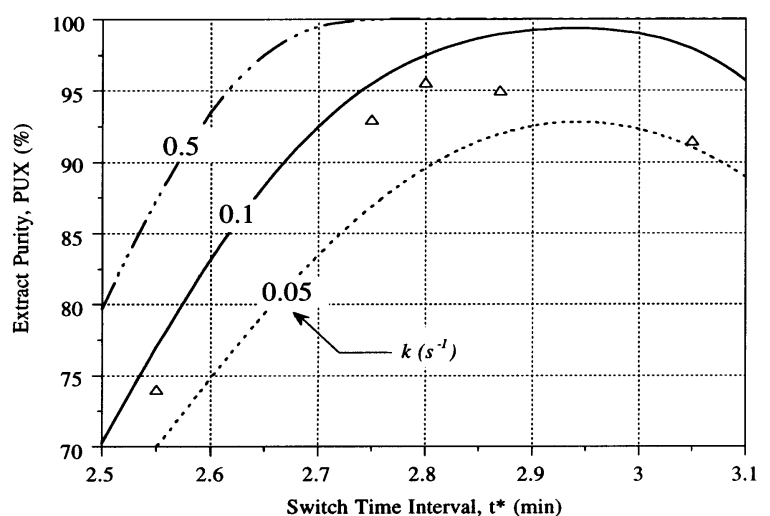

Fig. 8. Extract purity for bi-naphthol runs: comparison between experimental (points) and model (lines) true moving bed (TMB )predictions.

were measured using the 6-port valve of the Licosep SMB pilot to withdraw samples from the system. The samples were collected at each halftime period, after cyclic steady-state was achieved. The experimental performance parameters were determined by analysis of the extract and raffinate samples collected during a whole cycle.

The experimental performance parameters obtained are shown in Table 6. Purities and recoveries higher than $95 \%$ were obtained for both extract and raffinate using a switch time interval of 2.80 min. Figs. 8 and 9 show the experimental

Table 6

Ratio between fluid and solid interstitial velocities (true moving bed, TMB) and experimental performances obtained in the simulated moving bed (SMB) runs

\begin{tabular}{|c|c|c|c|c|}
\hline $\begin{array}{l}\text { Switch time interval } t^{*} \\
\text { (min) }\end{array}$ & $\gamma_{I}$ & $\gamma_{\mathrm{II}}$ & $\gamma_{\mathrm{III}}$ & $\gamma_{\mathrm{IV}}$ \\
\hline 2.55 & 5.499 & 3.669 & 4.085 & 3.046 \\
\hline 2.75 & 6.008 & 4.035 & 4.484 & 3.363 \\
\hline 2.80 & 6.136 & 4.127 & 4.584 & 3.442 \\
\hline 2.87 & 6.314 & 4.255 & 4.724 & 3.554 \\
\hline 3.05 & 6.773 & 4.585 & 5.082 & 3.839 \\
\hline $\begin{array}{l}\text { Switch time Interval } t^{*} \\
\quad(\min )\end{array}$ & $\begin{array}{l}\text { Extract purity PUX } \\
(\%)\end{array}$ & $\begin{array}{l}\text { Raffinate purity PUR } \\
(\%)\end{array}$ & $\begin{array}{l}\text { Extract recovery } \mathrm{RCX} \\
(\%)\end{array}$ & $\begin{array}{l}\text { Raffinate recovery RCR } \\
(\%)\end{array}$ \\
\hline 2.55 & 74.0 & 93.8 & 96.0 & 66.6 \\
\hline 2.75 & 93.0 & 96.2 & 97.3 & 91.6 \\
\hline 2.80 & 95.6 & 95.4 & 95.0 & 96.1 \\
\hline 2.87 & 95.0 & 92.8 & 91.8 & 95.8 \\
\hline 3.05 & 91.5 & 70.9 & 61.5 & 94.7 \\
\hline
\end{tabular}




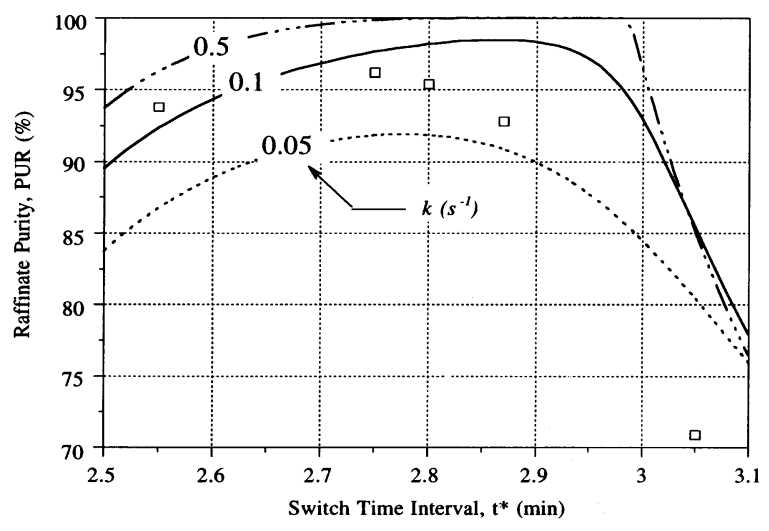

Fig. 9. Raffinate purity for bi-naphthol runs: comparison between experimental (points) and model (lines) true moving bed $(\mathrm{TMB})$ predictions.

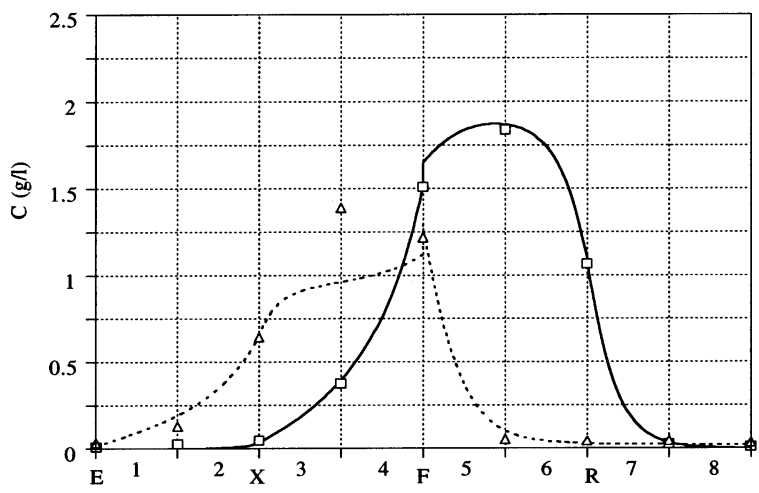

Fig. 10. Internal concentration profiles for the bi-naphthol system: comparison between experimental (points taken at half time period in the cyclic steady-state, simulated moving bed (SMB) operation) and simulated (steady-state true moving bed (TMB) operation) internal profiles. Operating conditions as in Table 5, switch time interval of $2.75 \mathrm{~min}$. purities obtained in the five bi-naphthol runs as well as the model predictions for different values of mass transfer coefficient, using the TMB model presented before. A good agreement between model and experimental results are obtained for $k=0.1 \mathrm{~s}^{-1}$. As it was shown in a previous work [9], it is valid to compare the experimental SMB results with the ones obtained by modeling using the TMB model, when two or more columns per section are used in the SMB system. Fig. 10 shows the SMB cyclic steady-state experimental internal profiles for the run with a switch time interval of $2.75 \mathrm{~min}$. Simulated results are also displayed using $k=0.1 \mathrm{~s}^{-1}$ (symbols are experimental results, lines for model simulation).

The separation of the chiral epoxide enantiomers (1a,2,7,7a-tetrahydro-3-methoxynaphth(2,3b)-oxirane), an intermediate from Sandoz Pharma (Basel, Switzerland), was carried out also using an 8-column configuration. Each column is $2.6 \mathrm{~cm} \mathrm{ID} \times 9.9 \mathrm{~cm}$ long. The separation used microcrystalline cellulose triacetate (particle diameter of $45 \mu \mathrm{m}$ ) as stationary phase and pure methanol as eluent at $25^{\circ} \mathrm{C}$. A linear + Langmuir model was proposed to describe the adsorption equilibrium isotherms [17]:

$q_{\mathrm{A}}^{*}=1.35 C_{\mathrm{A}}+\frac{7.32 \times 0.087 C_{\mathrm{A}}}{1+0.087 C_{\mathrm{A}}+0.163 C_{\mathrm{B}}}$
$q_{\mathrm{B}}^{*}=1.35 C_{\mathrm{B}}+\frac{7.32 \times 0.163 C_{\mathrm{B}}}{1+0.087 C_{\mathrm{A}}+0.163 C_{\mathrm{B}}}$

Table 7 presents the experimental conditions for the SMB operation. Using the simulation package presented in this work, a complete separation of both enantiomers was expected. Model parameters used in simulation were $\varepsilon=0.4, \mathrm{Pe}=$

Table 7

Experimental simulated moving bed (SMB) operating conditions for the chiral epoxide system

Feed concentration: $C_{\mathrm{A}}^{\mathrm{F}}=C_{\mathrm{B}}^{\mathrm{F}}=5 \mathrm{~g} / 1$

Switch time interval: $t^{*}=3.3 \mathrm{~min}$

Inlet/outlet flow-rates $(\mathrm{ml} / \mathrm{min}) \quad$ Internal liquid flow-rates $(\mathrm{ml} / \mathrm{min}) \quad$ Ratio between fluid and solid interstitial velocities

\begin{tabular}{lll}
\hline$Q_{\mathrm{E}}=12.36$ & $\mathrm{Q}_{\mathrm{I}}^{*}=33.74$ & $\gamma_{\mathrm{I}}=4.296$ \\
$Q_{\mathrm{X}}=8.64$ & $Q_{\mathrm{II}}^{*}=25.10$ & $\gamma_{\mathrm{II}}=2.940$ \\
$Q_{\mathrm{F}}=1.00$ & $Q_{\mathrm{III}}^{*}=26.10$ & $\gamma_{\mathrm{III}}=3.097$ \\
$Q_{\mathrm{R}}=4.72$ & $Q_{\mathrm{IV}}^{*}=21.38$ & $\gamma_{\mathrm{IV}}=2.356$ \\
\hline
\end{tabular}




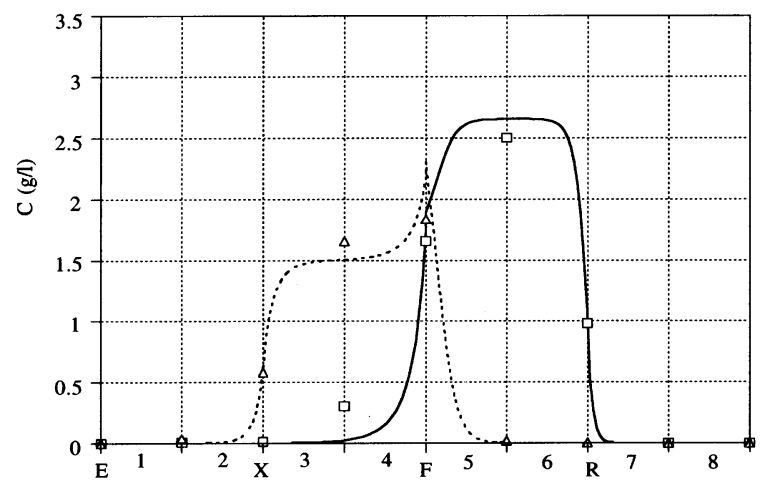

Fig. 11. Internal concentration profiles for the chiral epoxide system: comparison between experimental (points taken at half time period in the cyclic steady-state, simulated moving bed (SMB) operation) and simulated (steady-state true moving bed (TMB) operation) internal profiles. Operating conditions as in Table 7 .

2000, and $k=0.4 \mathrm{~s}^{-1}$ [17]. Experimentally, a raffinate purity close to $100 \%$ (PUR $=99.6 \%$ ) was obtained, but the extract purity was a little lower (PUX $=97.5 \%)$. This is a new experimental result which improves rather interestingly the purity performance reported for the same system in a previous work [17]. This improvement was achieved by using the right operating conditions following the simulation results obtained with the TMB model.

The internal concentration profiles were evaluated at cyclic steady-state (after 20 full cycles of continuous operation) and at half-time of a switch time interval. The steady-state TMB package was used to compare the theoretical and experimental internal concentration profiles. Fig. 11 shows the results obtained. The agreement between experimental and model results is good.

\section{Conclusions}

The main problem of the SMB operation consists in choosing the better solid (switch time interval) and liquid flow-rates. The SMB/TMB package is an important learning and training tool used to predict the effect of operating variables on the process performance, and so the choice of these best conditions for the SMB operation.
The regions for enantiomer separation can be numerically predicted, considering dispersion and mass transfer resistances phenomena. The mass transfer resistance phenomenon affects the separation region of both enantiomers. Moreover, this influence is emphasized when a high purity requirement is desired. The set of Figs. 5-7 provide a practical tool for choosing the better SMB operating conditions as a function of the feed flow-rate. The optimum is found following the path of equal extract and raffinate purities and will result from a trade-off between solvent consumption and adsorbent productivity, purity and recovery requirements, and system robustness.

The experimental operation of a SMB pilot unit was carried out for two illustrative examples of chiral separation. For the bi-naphthol system, purities and recoveries higher than $95 \%$ were obtained for both extract and raffinate. A 450-ml inventory of stationary phase was used, which corresponds to an adsorbent productivity of $68 \mathrm{~g}$ of racemic mixture processed per day and per liter of bed. The solvent consumption was $1.2 \mathrm{l} / \mathrm{g}$ of racemic mixture processed. For the chiral epoxide system, 97.5 and $99.6 \%$ pure extract and raffinate were obtained, respectively. The inventory of stationary phase used was $420 \mathrm{ml}$, which corresponds to an adsorbent productivity of $34 \mathrm{~g}$ of racemic mixture per day and per liter of bed, and a solvent consumption of $1.3 \mathrm{l} / \mathrm{g}$ of racemic mixture processed. The predictions of process performance and steady-state internal concentration profiles were carried out with reasonable agreement with experimental results.

\section{Acknowledgements}

Financial support from the European Community under the BRITE-EURAM Programme (Contract no. BRE2-CT92-0337) is gratefully acknowledged. Thanks are also due to R.-M. Nicoud, J. Blehaut and F. Charton (Novasep) and J. Kinkel (Merck and Georg-Simon-Ohm Fachhochschule) for helpful discussions and preparation of the chiral packings. 


\section{References}

[1] D.B. Broughton, C.G. Gerhold, U.S. Patent No 2,985,589 (1961).

[2] R.-M. Nicoud, LC-GC Intl. 5 (1992) 43.

[3] M.J. Gattuso, B. McCulloch, J.W. Priegnitz, Proc. of the Chiral Europe Symp., 1994.

[4] E. Francotte, In: G. Subramanian (Ed.), Proc. of the EUROTECH'98 Preparative and Process Scale Separations, Cambridge, UK, 1998.

[5] D.W. Guest, J. Chromatogr. A 760 (1997) 159.

[6] E. Francotte, In: S. Ahuja (Ed.), Chiral Separations-Applications and Technology, American Chemical Society, Washington, DC, 1996, Ch. 10.

[7] E. Francotte, in: H.Y. Aboul-Enein, I.W. Wainer (Eds.), The Impact of Stereochemistry on Drug Development and Use, Chemical Analysis Series, vol. 142, Wiley, UK, 1997, Ch. 23.
[8] R.-M. Nicoud, Recent Advances in Industrial Chromatographic Processes, Novasep, Nancy, France, 1997.

[9] L.S. Pais, J.M. Loureiro, A.E. Rodrigues, AIChE J. 44 (1998) 561.

[10] G. Bader, U. Ascher, SIAM J. Sci. Stat. Comput. 8 (1987) 483.

[11] L.S. Pais, J.M. Loureiro, A.E. Rodrigues, Chem. Eng. Sci. 52 (1997) 245.

[12] L.S. Pais, J.M. Loureiro, A.E. Rodrigues, J. Chromatogr. A 769 (1997) 25.

[13] Novasep, personal communication, 1995.

[14] D.M. Ruthven, C.B. Ching, Chem. Eng. Sci. 44 (1989) 1011.

[15] M. Mazzotti, G. Storti, M. Morbidelli, J. Chromatogr. A 769 (1997) 3.

[16] M. Mazzotti, M. Pedeferri, M. Morbidelli, Proc. of the Chiral Europe Symp., 1996.

[17] L.S. Pais, J.M. Loureiro, A.E. Rodrigues, J. Chromatogr. A. 827 (1998) 215. 